\title{
14-Tante Rosa: İsyandan varoluşa bir kadının hikâyesi
}

\section{Osman ORUÇı}

APA: Oruç, O. (2020). Tante Rọa: İsyandan varoluşa bir kadının hikâyesi. RumeliDE Dil ve Edebiyat Araştırmaları Dergisi, (Ö8), 183-190. DOI: 10.2900o/rumelide.814159.

\section{$\ddot{\mathbf{O} z}$}

Sevgi Soysal, çă̆daş Türk edebiyatında 1960 sonrası dönemde kadın sorunsalını enine boyuna irdeleyen isimlerden biridir. Ataerkil bir toplumda susturulan ve görmezden gelinen kadın öznenin sesi olmayı edebiyat düzleminde kendisine bir yol olarak seçmiş olan Soysal, çalışmaya konu olan Tante Rosa adlı eserinde geleneğin ve alışkanlıkların biçimlendirdiği bir kasabada yaşayan kapalı bir toplum içinde var olma savaşı veren sıra dışı bir kadının hayatını hikâye eder. Kadınlık içgüdüleriyle toplumun beklentileri arasında gidip gelen ama sonunda iç sesine kulak veren Tante Rosa tek başına, içinde yaşadığı toplumun ve onun kurumlarının, kutsallarının karşısına çıkar. Ataerkil bir anlayışın sürüp gittiği bir ortamda tek başına bir kadın özne olarak Tante Rosa'nın eyleme geçmesi, esasında onun bir kadın birey kimliği kurması manasını içerir. Fakat Tante Rosa'nın kendi bireyliğini kurarken ister istemez toplumla çatışması, onun ağır bir bedel ödemesi gerçeğini de beraberinde getirir. Erkek egemen bir zihniyetin şekillendirdiği toplumla ve bu zihniyetin taşıyıcı araçları olan toplumsal kurumlarla çatışmayı göze alamayan diğer hemcinslerinin tersine bir duruş sergilemesi son tahlilde ona bir şahsiyet kazandırır. Dünya edebiyatında romanın başlangıcından bu yana ortaya konan eserlerde kadının nasıl ele alındığı öteden beri edebiyat çevrelerinde tartışma konusu olmuştur. Bununla birlikte özellikle edebiyata feminist bir perspektiften yaklaşan edebiyatçılar arasında bu konu başat bir tartışma konusu hâlini almıştır. Hem Batılı örneklerde hem Türk edebiyatındaki örneklerde çoğunlukla erkek egemen/ataerkil zihniyetin talep ettiği bir hayat felsefesi doğrultusunda eylemlerini belirleyen kadının makbul/makul kadınlar olduğu, tam tersine bu zihniyetle bir çatışma yürüten kadınların yalnızlaştırıldığı, cezalandırıldığı, dahası şeytanlaştırıldığı görülür. Çalışmaya konu olan romanın başkahramanı Tante Rosa da aynı süreçleri yaşar. Bu çalışmada, Tante Rosa'nın bireysel tercihlerini yaşamak pahasına toplum tarafından nasıl ve niçin hayattan izole edildiği ve bu soyutlamaya karşın Tante Rosa'nın nasıl bir tepki verdiği ve kadın bir birey olarak varoluşunu nasıl tamamladığı feminist eleştiri bağlamında açı̆̆a çıkarılmaya çalışılmıştır.

Anahtar kelimeler: Sevgi Soysal, Tante Rosa, feminizm, varoluşçuluk, kimlik

\section{Tante Rosa: The story of a woman from insurrection to existence}

\begin{abstract}
Sevgi Soysal is one of the authors in contemporary Turkish literature who thoroughly examines the issue of women in the post-1960 period. Soysal chose to be the voice of female subject that is silenced and ignored in a patriarchal society as a way for herself in the literary plane and she tells the life story of Tanta Rosa, an extraordinary woman struggling to exist in a closed society shaped by tradition and habits, in her work, which is the subject of the study. Tante Rosa, going back and
\end{abstract}

Dr. Öğr. Üyesi, Bayburt Üniversitesi, İnsan ve Toplum Bilimleri Fakültesi, Türk Dili ve Edebiyatı Bölümü (Bayburt, Türkiye), osmanoruc@bayburt.edu.tr, ORCID ID: 000o-0002-2610-185X [Makale kayit tarihi: 13.09.2020-kabul tarihi: 20.11.2020; DOI: 10.29000/rumelide.814159]

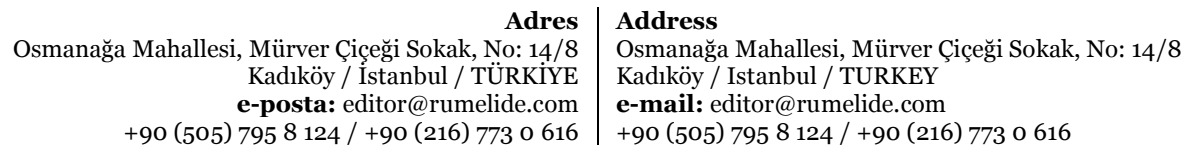


forth between her feminine instincts and the expectations of the society,eventually listens to her inner voice and confronts the society, its institutions and sacred values. In an environment where a patriarchal understanding persists, actions of Tante Rosa by herself as a female subject essentially means establishing anindividual female identity. However, inevitable conflict of Tante Rosa with the society while establishing her own individuality implies that she pays a heavy price in the end. In the final analysis, she gains a new personality in her struggle against the opposite stance of other women, who cannot afford to conflict with the society shaped by a male-dominated mentality, and the social institutions that are the defenders of this mentality. How women are examined in the literature works that have been created since the beginning of the novel genre has been a subject of discussion in literary circles for a long time. Furthermore, this issue has become a dominant topic of discussion, especially among those who approach literature from a feminist perspective. It is observed in both the examples of Western and Turkish literature that women who determine their actions according to a world view demanded by male-dominant/patriarchal mentality are generally considered as reasonable/acceptable women while the women who have a conflict with this mentality are isolated, punished, and moreover demonized. Tante Rosa, the protagonist of the novel that is the subject of the study, experiences the same processes. This study will try to reveal how and why Tante Rosa is isolated from life by the society to live in line with her individual preferences and how she reacts against this isolation and how she completes her existence as an individual woman in the context of feminist criticism.

Keywords: Sevgi Soysal, Tante Rosa, feminism, existentialism, identity

\section{Giriş}

Dünya edebiyatı genellikle erkeğin gölgesinde, erkeğin belirlediği sınırlar çerçevesinde ve erkek tarafından bahşedilen bir kimliği koşulsuz kabul eden yahut buna boyun eğen ve tabiatıyla erkek egemen toplum tarafından onaylanan "melek" tipinde kadın roman kahramanlariyla dolu olmakla birlikte; geçmişten bugüne saylları artmakla beraber yine de bu fotoğrafta küçük bir yekün teşkil eden kendi iç sesine kulak verip hayatını ona göre tanzim eden ve bu yüzden toplum tarafından dışlanıp cezalandırılan "canavar/şeytan" tipi kadın kahramanlara da yer vermeye başlamıştır. Batı edebiyatında bunun en tipik örneği Gustave Flaubert'in en bilinen romanlarından olan Madame Bovary'deki Emma Bovary karakteridir. Türk edebiyatında ise akla gelecek ilk örnek Halit Ziya Uşaklıgil'in, Madame Bovary romanından esinlenerek yazmış olduğu Aşk-ı Memnu romanındaki Bihter karakteridir. Her iki karakter de kendilerine sunulanla yetinmeyip toplumun beklentilerine aykırı eylemler içerisinde bulundukları için yazarları tarafından romanların sonunda "öldürülerek" cezalandırılmışlardır.

Türk romanının başlangıcından itibaren romancılarımızın kadına yaklaşımları hep ataerkil bir zihniyetin dışavurumu biçiminde tezahür eder. Namık Kemal'in İntibah romanında Mehpeyker, hayatının bir noktasından sonra samimi bir âşık olarak okuyucunun karşısına çıksa da, romancı onu, günahkâr bir geçmişe sahip olmasından ötürü asla affetmez ve romanın sonunda cezalandırır. Ahmet Mithat Efendi'nin Felatun Bey ile Rakrm Efendi romanında topluma örnek bir tip olarak sunulan Rakım Efendi'nin bütün çapkınlıkları romancı tarafından okuyucuya hoşgörülü bir yaklaşımla verilir. Rakım Efendi'nin bir yandan metresi Josefino ile gönül eğlendirmesi, öte taraftan kendi hayat felsefesi doğrultusunda eğiterek bir biçim verdikten sonra evlenmeye layık bulduğu Canan'a karşı tutumu hep erkek egemen bir dünya görüşünün yansımalarıdır. Bu durumdan ne Josefino rahatsızdır ne de Canan. Zira toplum nazarında Rakım Efendi'nin çapkınlık yapmasında bir beis yoktur. Ancak aynı hareket tarzı, Aşk-ı Meтnu romanında Bihter, Eylül romanında Suat örneğinde olduğu gibi, bir kadın

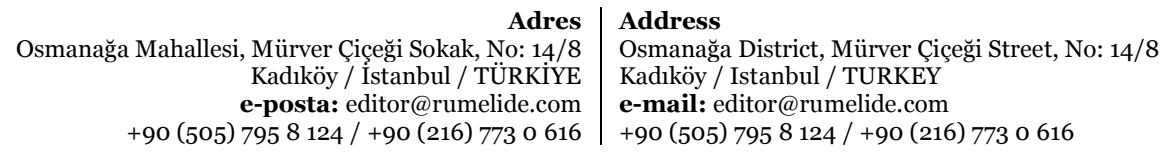


tarafından sergilenince ataerkil zihniyetin şekillendirdiği kolektif bilinç vakit kaybetmeksizin harekete geçer ve "ahlaksız kadın" linç edilir.

20. yüzyılın başlarından itibaren kamusal hayatta kadının daha fazla görünür olması, erkekle eşit bir konum talep etmesi, feminist düşüncenin giderek güçlenmesi ve edebiyat düzleminde kadın romancıların varlık göstermeye başlaması ile erkek yazarların tekelinde olan edebiyat dünyası kısmen de olsa kadına, kadın sorunsalına yeni bir pencereden bakmaya başlamıştır. O güne değin erkek romancıların anlattığı kadınlar bu defa hemcinsleri olan kadın romancılar tarafından kadın duyarlılı̆̆ının bütün imkânları yürürlüğe sokularak anlatılmaya başlanmıştır.

Feminist eleştiri, ataerkil düzenin bütün kurumlarında olduğu gibi edebiyatta da kadına karşı takınılan aşağılayııı/horlayıcı tutumu ortaya çıkarmak amacıyla, feminist hareketin bir parçası olarak 1960'lardan itibaren görülmeye başlanmış ve çeşitli yorum biçimleriyle bugüne kadar gelmiştir. Gündelik yaşamda ezilen ve aşağılanan kadının, erkek yazarların yazdıkları romanlarda da aynı eril bakış açısıyla ele alındığı, Marksizm'in toplumsal alt-yapı kurumları olarak belirlediği politik ve ekonomik alanda ezilen kadının, toplumsal üst-yapı kurumları olan sanat ve edebiyat düzleminde de aynı muameleye tâbi tutulduğu görülür. Bu anlamda edebiyat, ataerkil düzenin kadın için belirlediği alt konumu pekiştiren, bu bakış açısını yeniden üreten bir araç vazifesi görmüştür. Ataerkil yapının güdümünde yaşamayı kabul eden kadın, eril zihniyet tarafından, kendi doğasına sadık bir özne olarak değerlendirilirken; bağımsızlığına düşkün, çıkarını gözeten, erkeklerin kendisine biçtiği kişiliği/kimliği kabullenmeyen kadın kendi tabiatına ihanet eden bir kişilik olarak ele alınmıştır. Zira ataerkil toplumlarda üstün değerler erkeğe; aşağı değerler kadına özgüdür. Bu bağlamda erkek üstün ve merkezdir (Moran, 2012: 260). Bu bakış açısına göre erkeğe rağmen kadın öznenin varlı̆̆ından söz edilemez.

\section{Bir varoluş pratiği olarak Tante Rosa'nın isyanı}

İnsanın özgür olmaya mahkûm olduğunu ifade eden Sartre (2017: 47) insanlık durumunu dünyada bulunmaktan öte, dünyada olmak biçiminde açıklar. Bu anlamda var olmak, insanın kendi varlığını seçmesi, etrafını çevreleyen gerçekle yüzleşmesi ve onunla çarpışmasıdır. Öte yandan Gasset, insanın kendisi için, kendi amaçları doğrultusunda sergilediği eylemlerin insani sayılabileceğini ve insani olayın her zaman kişisel bir olay, kişinin yaratıcı öznesi olduğu eylemler olduğunu söyler (2011: 25). Tante Rosa aykırı ve yabancı, kadınlı̆̆ını sınırsızca yaşayan, sıradışı bir kimlik ve kişiliğe sahip, tutunamayan bir kadın, "başına buyruk ve alışılmadık istekleri olan birisidir"(Erkman-Akerson, 2013: 50). Toplumun ona dayattığı kurallardan, tekdüze hayattan kaçarak ve kadınlığını özgürce yaşamak uğruna eşini ve çocuklarını bırakarak şehre gider. Aidiyetin ve toplum tarafından dayatılan kimliğin bir kader olmadığının farkına varır. Bu anlamda o, tanımlanmış kimliği reddeder ve kendi eylemleri ve tercihleriyle edinilmiş bir kimliği kabullenir.

Kimlik keşfedilmesi gereken bir şey değildir, aksine tamamıla icat edilmesi gereken, bir çabanın hedefi, bir amaç, kişinin en baştan inşa etmesi gereken veya alternatif teklifler arasından seçip sonra uğrunda mücadele ederek elden edebileceği bir şeydir (Bauman, 2019: 25). Varoluşçu felsefenin onayladığı biçimde kendi kendini kuran ve 'insan' olmayı başaran Tante Rosa bu yönüyle 'herkes'ten ayrılır. Zira o, kimliğini kendi rızasıyla tesis etmenin peşinden gider. Öte taraftan kalabalık/herkes, kendilerine tercih hakkı tanınmadan, başkaları tarafından zorla dayatılan tek tipleştirici bir kimlik yükünü sırtlanırlar, kimlik tercihinden men edilmiş bir sürü hâlinde yaşarlar (Bauman, 2019: 51).

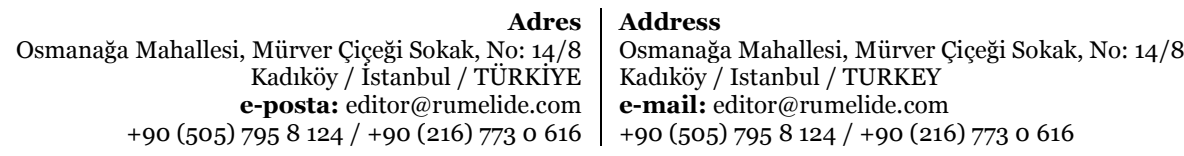


Tante Rosa, toplumdan gelen tepkileri bir başına göğüslemeyi göze alıp kadınlık içgüdülerinin peşinden yol alır ve aykırı da olsa bir birey olmayı başarır. Hayatını kuşatan, sınırlayan herkesi ve her şeyi bırakarak alıp başını gider. Bir rutin halinde her pazar kiliseye giden, sonrasında hep birlikte kaz kızartması yiyen robotlaşmış topluluğun/kalabalığın bir parçası olmaktan istifa eder ve birey/insan olmayı seçer. Ancak onun bu aykırı tutumu toplum tarafından hoş karşılanmaz ve kendisi aforoz edilerek yalnız birakılır.

Tante Rosa erkek egemen dünyaya başkaldıran bir kadındır. Dışarıda bırakılmışlığına, dışlanmışlığına rağmen hayata karşı her daim iyimser bir duruş sergiler. Yaşamını devam ettirirken kendisinden beklenilen davranış biçimlerini tekrarlamak yerine kadınca bir tavır ortaya koyar. Sıradan bir anne olmayı, erkeğinin gölgesi altında bir eş olarak yaşamayı kabul etmez ve toplumun kendisine giydirmeye çalıştığı kimliği reddederek eyleme geçer ve çekip gider. Zira "insan ilkin, temel olarak eylemdir"(Gasset, 2011: 43). Kavga ederek, savaşarak kendi yaşamını yapılandırır ve nihayetinde var olur. Tante Rosa bir anlamda 'yasakları çiğnemek ve çekip gitmek'tir. Alışılmış olandan, bir rutin hâlini alan her şeyden kaçar.

Çocukluğunda 'at cambazı' olmak ister ama olamaz, buna izin verilmez. Ailesi onu rahibe okuluna verir. Fakat Tante Rosa buradaki sistemle çatışır. Burada kendisine öğretilenlere ayak uyduramaz. Rahibeler tarafından 'içindeki arzulara gem vuramayan günahkâr bir kız, içini öldürmeyi bilmeyen biri' olarak suçlanır. Vücudunun kötü bir şey olduğunu öğreten rahibelere, 'ben içimi öldüremem, çünkü içim prensestir.' cevabını verir. Romanın birkaç yerinde tekrarlanan bu ifade Tante Rosa'nın kendisine duyduğu büyük öz saygının dışavurumudur. $\mathrm{O}$, ailenin, toplumun, kilisenin bireye dayattığı görevleri ve ahlak kurallarını sahiplenmeden yoluna devam eder. Zira "etik görevin ve ahlaki kaygının amacı bireyselliğin ve yüzün reddi; hatta silinmesidir"(Bauman, 2019: 52-53). Kendiliğini yaşamak uğruna toplumun bireyi, özgün kimliği imha eden kabullerini görmezden gelerek eylemlerini tayin eder. Rahibeler okulundaki yasakları ve kabulleri hiçe sayar. Bu yüzden Paskalya Yortusu gösterisinde melek rolünde sahneye çıkacakken, ceza olarak ona 'yoksul' rolünü layık görürler. O akşam dünyanın en başarılı yoksul çocuk rolünü oynar. Tante Rosa'nın münasebetsizliklerine daha fazla tahammül edemeyen rahibeler, onu okuldan atarak ailesinin yanına gönderirler.

Rahibeler okulundan atıldıktan sonra Tante Rosa genç, özgür bir kıza dönüşür. Okulun kendisini bu şekilde cezalandırmasına cevap sayılabilecek bir eylemde bulunur ve genç kızlığa adım attığı dönemde komşunun oğlu Hans'tan hamile kalır ve 'namusu kirlenmiş bir aile kızı olmamak, zavallı bir piç kurusu doğurmamak için’ onunla evlenir. Bu evlilik onu mutlu kılmaz, çünkü özgür değildir. Toplumun ondan beklediği çocuklarının müşfik annesi ve kocasının fedakâr, vefalı karısı rollerini kabul etmez ve geride bir mektup birakarak evi terk eder. Onun bu eylemi, uyumsuz bireyin konformist bir hayat felsefesiyle bir robot gibi yaşayıp giden ve birbirinin kopyası olan insanların oluşturduğu toplumsal yapıya, bu yapının önceliklerine, kıymet hükümlerine iltifat etmediğini işaret eder.Göreneklerin, toplumsal kabullerin kayıtsız şartsız uygulayıcısı (eylem uygulayıcısı) olan insan ötekileşmiş ve temel insani niteliğini yitirmiştir. "Görenekleri izledikçe robot gibi davranırız, toplumun ya da topluluğun izdüşümünde yaşarız. Ama toplum ya da topluluk ne insani ne de insanüstü bir şeydir, yalnızca salt göreneklerin mekanizmasıyla etkili olur, kimsenin sorumlu ve bilinçli yaratıcı öznesi olmadığı göreneklerin"(Gasset, 2011: 28). Ataerkil toplumsal düşüncenin ondan beklediği "evdeki melek" rolünü terk eden Tante Rosa, romanın ilerleyen sayfalarında kolektif bilinç tarafından şeytanlaştırılır. Zira Tante Rosa düzeni tahkim eden toplumsal kurumlara (aile, kilise, gelenek) savaş ilan etmiştir.

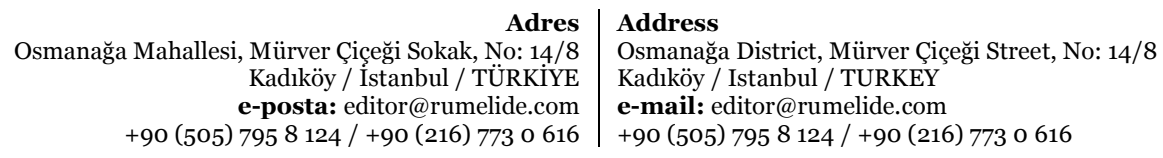




\begin{abstract}
"Bir mektup bıraktı Tante Rosa arkada, üç çocuk bıraktı, biri emzikte, kaz kızartması ve elma pastası yapmasını, yemek masası örtülerini kolalamasını, dolapları yerleştirmesini öğrettiği hizmetçi kızı bıraktı. Margarita ekili bir küçük bahçe, tahta merdivenli, yüksek tavanlı, çalar saatli bir ev bıraktı, her Pazar sabahı kiliseye giden, her Pazar öğleden sonra koynuna giren kocayı bıraktı, şapka giyen komşu kadınları, sümüklü çocuklarını bıraktı, onların kocalarını, onların da kaz kızartmalı hayatlarını bıraktı, kiliseyi bıraktı, çan seslerini, org seslerini, Noel şarkılarını bıraktı, kiliseden dönen çocukların attığı kartopuyla delinen camı tıkadığı sol memesini, yüreğini yağ tabakasıyla örten sol memesini bıraktı. Gitti. Gitti fabrika bacalarının, gemi düdüklerinin oraya, tramvaylarda herkesin birbirlerinin ayaklarına bastığı ve pardon demediği ve ne merhaba ne de günaydın demediği insanların oraya gitti, Pazar günü öğleden sonraydı, akşamdı ya da, yollara düştü, arkada soluk menekşeler arasında katlanmış mektuplar bıraktı, gelin elbiseleri, duvaklar biraktı"(Soysal, 2004: 36).
\end{abstract}

Tante Rosa bu hareketi yüzünden köyün kilisesi tarafından cezalandırllarak aforoz edilir. "Tante Rosa'nın özellikle kilise tarafından aforoz edilmesi toplum tarafından yabancılaştırılmanın simgesel boyutlarını içermektedir. Bir toplumdaki dinî kurumlar, toplumun bir kısmını yansıtması bağlamında değerlendirildiğinde; görünüşte kilise tarafından aforoz edilen Rosa'nın aslında toplum tarafından, toplumdan aforoz edildiği anlamı çıkarlacaktır"(Çevirme, 2011: 49). Tante Rosa bu saatten sonra toplumsal hayattan izole edildiği için, kendine sığınır ve burada hayalleriyle yaşayan bir hayalperest portresi çizer.

"Tante Rosa en büyük açılmayı küçük Alman kasabasından büyük kente geçtiğinde yaşar. Kendisine
öğretilen ve dayatılan düzeni bir anda yıkar ve arkasında çocuklarını ve eşini bırakarak tek başına
büyük kente gider. Burada mekân değiştirme ile dışarıya açllma arasında bir paralellik vardır. Tante
Rosa, yaşam düzenini sı sı sı ve kolaylıkla değiştirir, mekânları da aynı kolaylıkla değiştirir. Her
düzen değişimi bireyselleşme açısından atılmış bir adım gibidir"(Erkman-Akerson, 2013: 51).

Kasabada ilk evliliğinde toplumun beklentileri etken iken, kente geldikten sonra erkeklerle olan ilişkilerinde tek karar mercii kendisidir. "Tante Rosa'nın ilk ilişkisi bariz bir şekilde onun bireyselleşmesini engellemiş ve özgürlüğünü kısıtlamıştır. Diğer ilişkilerinde ise sevdiği adamlarla beraber olur; sıkıldığında ya da artık sevmediğini anladığında da onları terk eder" (Erkman-Akerson, 2013: 54).Bu noktada denilebilir ki Tante Rosa, bu hareket tarzıyla ataerkil zihniyeti protesto etmiştir. Zira öteden beri erkek egemen zihniyetin şekillendirdiği toplumda kadın bir birey olmaktan ziyade güdülen, tüketilen bir varlıktır.Bu bakış açısına örnek olması bakımından Hüseyin Kılıç'ın Antikçağdan Günümüze Batıda Kadın ve Cinsellik adlı eserinde Rousseau'dan aktardığı aşağıdaki satırlar son derece çarpıcıdır.

\begin{abstract}
"Kadın, erkeğe bağlı olmak, onun haksızlıklarına boyun eğmek için yaratılmıştır. Onlar, olumlu bilimlerde başarılı olmak için gereken doğru görüş ve özene sahip değildir. Cinsel görevlerde, erkeğin koyduğunu sandığı eşitsizliklerden, kadının yakınmaya hakkı yoktur. Karnında çocuk taşımaya gücemli kılınmış olanın, öbürüne karşı sorumlu olması, doğanın gereklerindendir. Her kadının da dört çocuk doğurmasını sağlamak, kesinlikle gereklidir. Çünkü, kadının yaratılışındaki asıl amaç, dünyaya çocuk getirmektir. Doğa ve aktörenin genel yasalar aracılığıyla kadının analık durumunu korumasından başka ne amacı olabilir? Kadın, kadın olarak kaldıkça üstün, erkeklik savına kalkıştıkça geri kalır. ... Erkeklerin hoşuna gitmek, onlara yararlı olmak, kendilerini sevdirmek ve saydırmak, küçükken büyütmek, büyüyünce bakmak, avutmak, yaşamı zevkli kılmak... İşte kadınların görevleri"(Rousseau, 1956'dan aktaran Kılıç, 2000: 238-239).
\end{abstract}

Ataerkil zihniyetin şekillendirdiği toplumda kadın erkeğe rağmen bir özne olarak varlık gösteremez. Kadının varlığı kayıtsız şartsız erkeğinin yanında, ona biat etmesiyle mümkündür. Toplumun beklentilerini karşıladığı takdirde kadının bir değeri/anlamı vardır. Bu bakış açısına göre kadın erkeğin güdümüne muhtaç, kendi eylemlerine hükmedemeyen iradesiz bir canlıdır. 
"Kadın, eğlence yaşamına ve özgürlüğe ancak evlendikten sonra kavuşabilir. Cehennem olup yakan, melekleşip erkeğin canına can katan, şeytanın aracı, belki de ta kendisi olan kadının evlenip birisine bağlanmaktan öte hiçbir usçu umarı yoktur!...

Kadınlar, usları olduğu hâlde düşünemeyen, yürekleri olduğu halde duyguları olmayan, gözleri olduğu halde bakmaktan korkan, kulakları olduğu hâlde söylenenleri duymayan, salt anlamsızlıkları sergilemek için toplum içine çıan, sürekli olarak da anlamsız söz ve öğrence (ders) dinlemeye yargılı yaratıklardır."(Montesquieu, 1963'ten aktaran Kılıç, 2000: 234).

Kente taşındıktan sonra kadın bireyliğini yürürlüğe sokan Tante Rosa, bu defa, âdeta ataerkil zihniyetten intikam alırcasına erkekleri tüketmeye başlar. Gittiği büyük kentte keman çalan güzel bir koca bulur. Gazete bayisi olur. İkinci kocasından da iki çocuğu olur. Keman çalan güzel kocası günün birinde aniden ölür. Tante Rosa parasız kalır. Yeni bir iş kovalamaya başlar. Mezar bakımı işine girer. Yine evlenir. Bu arada hiç umursamadan, kadınlık içgüdüsüyle başka erkekleri de evine alır. Sıradan, alışıldık olandan ve tekrardan sürekli kaçan Tante Rosa üçüncü kocasını evden kovar.

"Sabah olmadan git ve kimse gelmesin. Ben kendi çirkinliğimle yetinmeye alıştım. Sabrın sonu selamet değildir.

Yarın yine kahveye gidip strudel yiyeceğim, o haddini bilmez herifi tutup evime, yatağıma getireceğim"(Soysal, 2004: 48).

Kendi kadınlığının, kendi aklının, kendi doğrularının ekseninde bir hayat sürer kentte. Kendisi dışında hiçbir şey umurunda değildir. Kendi gerçekliğini hiçbir sınır tanımadan, hiçbir şeyi umursamadan yaşar. Onun bu tercihi toplum tarafından anlaşlamaz ve kabullenilemez. Fakat Tante Rosa, toplumun kendisine yönelik bu olumsuz, dışlayıcı tavrını ciddiye almak yerine onunla alay eder. Âdeta onun bütün eylemleri, toplumsal yapıyı idare eden yerleşik düzenle bir çatışma hâlindedir. "Romanda, terim olarak 'toplum'un bütün değerlerine, çok ince, estetize edilmiş bir alayla başkaldıran, onu yok sayan, toplumun onu ötekileştirmesi ve yadsıması üzerine toplumu kendisine ötekileştiren ve onu yok sayan bir kadının düşünsel anatomisi verilir" (Çevirme, 2011: 52).

İşsiz, parasız, aç kalır. Tuvalet bekçiliği yapar. Anlaşılmamış ince yürekli biri olarak varoluşunu insanca gerçekleştirmenin peşindedir. Ama hayat buna izin vermemektedir. Kendi aykırılığını, toplum içindeki iğretiliğini şöyle değerlendirir:

"Herkesin sadece bir kez boğulmaya hakkı vardır. Ya ben; boğul babam boğul, sonra yine yaşamakta devam eder bul kendini. ... Gülünç bir ihtilalim ben, kötü bir askerî cuntayım. Asker olmuş gülünç bir soytarı gibi gülünç bir başkaldırma. ... Ama yaşamak zorunda olmak, sürdürmek, ısrar etmek. Bu Tante Rosa demektir. ... Tante Rosa; iş aramak demektir. Âşık ve koca aramak demektir. Âşık ve koca, âşık ve koca"(Soysal, 2004: 68).

Bir ara bir randevu evinde kasiyerlik yapar. Bu sırada buradaki kadınlara özenir fakat diğer kadınlar tarafından onun bu tavrı büyük bir tepkiyle karşılanır. Toplumun sürekli bir biçimde bireyi gözetim altında tutması, onun birey olmasına izin vermemesi, yıllardır 'kendi olma' savaşı veren Tante Rosa'yı bir yerde yorar.

\footnotetext{
“-Vay utanmaz, ben de niçin kasanın başında değil diyordum.

-Vay haddini bilmez.

-Vay ahlaksiz.

-Vay namussuz.

-Orospu vay!

...bir örgütün içinde olmak gerektiğini, anladı.
}

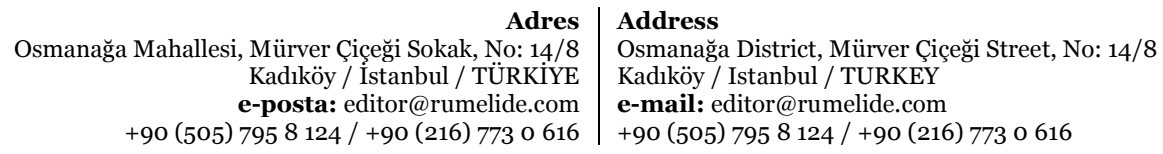


Şu ya da bu çemberin içine girmemiş, girememiş bir bireyin gebermekten başka hakkı olmadığını anladı" (Soysal, 2004: 72-73).

Yaşlılığında başkalarına yazdığı mektuplarla yaşadığını, orada olduğunu ispatlamaya, göstermeye çalışır. Yıllarca içinde taşıdığı yitme, tıkanma duygusuna rağmen yine de o, insanlara, topluma 'ben bir kadınım ve ben buradayım' demekten vazgeçmez. Kendisinin görmezden gelinmesine tahammül edemez. Yaşamının son anına kadar tek başına bir kadın olarak var olmanın savaşını verir.

"Yaşlandı Tante Rosa... Bir Noel ağacı gibi süslü, pırıltılı olmalıyım. Göze batıcılığım, çirkinliğimi, yaşlılığımı aşmalı. Gülebilirler, alay edebilirler, ama görmeden geçemezler. Bunca yaşanmışlı̆̆ın yanından insanların bakmadan, aldırışsız geçip gidivermeleri, hayır bunu istemiyordu! Yüreğimi attım ortalığa kimseler üstüne basmadan geçti." (Soysal, 2004: 83-84)

Öncesiz ve sonrasız, bağlantısız ve belgesiz olarak sürdürdüğ̈̈ yaşamı bir tren kazasıyla son bulur. Yaşarken olduğu gibi Tante Rosa'nın ölüsü de ortada kalır. Hiç kimse ve hiçbir kurum sahip çıkmak istemez. Kimliğinde 'dinsiz' yazıyor olmasından ötürü Tante Rosa yine o büyük kütlenin dışında kalır. Hayalperest bir insan olan Tante Rosa içinde yaşadığı toplumun kabullerine başkaldırır, umarsızca kadınlı̆̆ını yaşar. Ancak onun bu seçimi, toplum tarafından aforoz edilme, yalnız bırakılma ve yabancılaştırma ile cezalandırılır. Yerleşik toplum düzeni ona hayat hakkı tanımaz. "Toplum tarafından yadsınmış, ötelenmiş olan Rosa" (Çevirme, 2011: 49) ölümünde de yalnız bırakılır.

\section{Sonuç}

Tante Rosa, kalabalı̆̆ın aksine düzenin buyruklarına sırt çevirerek, otoritenin çizmiş olduğu sınırları ihlal ederek bir varoluş pratiği sergiler. Bireysel özgürlüğü ve aidiyetin sağladığ güvenlik hissi arasında bir seçim yapar ve "bir ortamın çaresi tutsağı" olmak yerine, gelenek/toplumsal kurumlar tarafından tanımlanmış "kimlik kafesi"nin dışına çıkarak kendi olmak pahasına tek başına toplumun kabullerini hiçe sayar ve isyan ederek hayatı boyunca bir varoluş sürecini tecrübe eder. Tante Rosa, geleneğin dayattığı eylemlerin uygulayıcısı olan toplumdan, eylem yaratıcı yanıyla ayrılır ve bireysel kimliğini elde eder. Ailesinin, üvey babasının, kocasının, geleneğin, kilisenin dayattığı davranış kalıplarını reddeder, bireyliğini yaşamak adına cesaretle eyleme geçer ve bir kimlik inşasının öznesi olur. Toplumun kadından beklediği çocuklarının müşfik annesi, kocasının her koşulda vefalı eşi ve evinin marifetli hanımı görevlerini kabul etmeyen Tante Rosa, toplum tarafından kadına biçilen kimliği sahiplenmez ve kendi seçimleri, kendi eylemleriyle inşa edeceği bir bireyleşme/kimlik edinme sürecinin içine girer. İçinde yaşadığı toplumun ve onun müesseselerinin bireyi bir kalıba sokan hazır kimliği daha çocuk yaşta reddederek tesis etmeye başladığı şahsiyetini ilerleyen zamanlarda özgür bireysel tercihleriyle biçimlendirir. Tante Rosa'nın büyük kütleye rağmen tekil bir özne olarak bir irade ortaya koyması, özellikle bir kadın birey olarak erkek egemen dünyaya başkaldırması, onun isyanını bir varoluş pratiğine dönüştürür.

Türk edebiyatında feminist damarın önemli isimlerinden biri olan Sevgi Soysal'ın bireysel tarihinden de izler taşıyan Tante Rosa bu anlamda tam bir karakter örneğidir. O, kadınlık içgüdülerini/bireyliğini özgürce yaşamak adına konforlu sayılabilecek bir düzeni gözünü kırpmadan ardında bırakır ve bireysel kadın kimliğini inşa etmek üzere yola çlkar. Tante Rosa bu uğurda büyük bedeller öder; toplum tarafından ötekileştirilir, kilise tarafından aforoz edilir, yalnız kalır. Bununla birlikte onun hayatı boyunca kendi eylemlerini özgürce tayin etmesi, bu eylemlerin bedelini ağır bir şekilde ödemesi son tahlilde onun bir birey kimliği elde ettiğinin ispatıdır. Zira eylemlerinin eyleyeni de, bu eylemlerin neticesinde ortaya çıkan gerçekliğin yükünü sırtlayan da kendisidir. Bu bağlamda kendi düşündüğü, kendi istediği gibi yaşayan, kendi eylemlerinin yaratıcı öznesi olan Tante Rosa varoluş/insan oluş

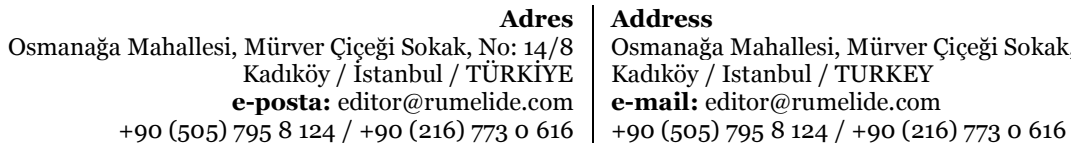


pratiğini hayatı boyunca tecrübe etmiş, bir birey olarak toplumla çatışmayı göze almış, 'kimliğin öz yurdu olan savaş meydanında'(Bauman, 2019: 95) bireysel kimliğini inşa etmeyi başarmıştır.

\section{Kaynakça}

Bauman, Z. (2019). Kimlik. Çev.Mesut Hazır, Ankara: Heretik.

Çevirme, E. A. (2011). Sevgi Soysal'da Sıradışı Bir Kadın Portresi: Tante Rosa. Roman Kahramanları, $6,47-54$.

Erkman-Akerson, F. (Derleyen). (2013). Edebiyatımızda Bireyselleşme Serüveni. İstanbul: Ayrıntı.

Gasset, Y. O. (2011). İnsan ve Herkes. Çev.Neyire Gül Işık, İstanbul: Metis.

Kılıç, H. (2000). Antikçağdan Günümüze Batıda Kadın ve Cinsellik. İstanbul: Otopsi.

Moran, B. (2012). Edebiyat Kuramlart ve Eleştiri. İstanbul: İletişim.

Sartre, J. P. (2017). Varoluşçuluk. Çev.Asım Bezirci, İstanbul: Say.

Soysal, S. (2006). Tante Rosa. İstanbul: İletişim. 